\title{
A Mobile-Based Fuzzy System for Diagnosing Syphilis (Sexually Transmitted Disease)
}

\author{
Alaba T. Owoseni \\ Department of Computer Science, Interlink Polytechnic, Ijebu Jesa, 233114, Nigeria \\ Email: magnustimmmy@gmail.com \\ Isaac O. Ogundahunsi, Seun Ayeni \\ Interlink Polytechnic, Ijebu Jesa, 233114, Nigeria \\ Email: \{jideogundahunsi, seun.ayeni\}@yahoo.com
}

\begin{abstract}
The high rate at which Africans die of syphilis yearly has been majorly attributed to the uneven ratio of the patients to competent medical practitioners who provide Medicare. This mortality rate has always drawn the attention of researchers and different approaches had been used to bring the rate down. This paper provides a software solution that personifies the expertlike way of providing diagnostic service to patients who suffer this disease. It is capable of making approximate diagnosis based on uncertainties. The system has been structured into five components: user interface, fuzzification, knowledge base, inference engine and defuzzification. The user interface uses a graphic user interface based method of human-computer interaction while the fuzzification component has transformed crisp quantities into fuzzy quantities using both interval-valued and S-curve membership functions. The reasoning has been achieved using root sum square (RSS) method and transformation of fuzzy values to scalar ones was through weighted average method. This system was tested and found effective.
\end{abstract}

Index Terms-Fuzzy System, Mobile Based Fuzzy System, Membership Functions, Interval valued membership function, Root sum square, Diagnosis of Syphilis.

\section{INTRODUCTION}

Africa has been hypothetically found to be synonymous to diseases due to the high rate at which the continent is affected by various diseases. There are various deadly diseases that are faced by people residing in Africa but some of these are under medical control. Syphilis (sexually transmitted disease) caused by Treponema pallidum [1] is one of these diseases. It is a disease that is prevalent in lesser and more developed countries [2]. Although Syphilis is mostly referred to as a sexually transmitted disease (STD) but, it could be congenitally transmitted or transmitted through blood transfusion [3]. There are various reasons for the prevalence of this disease among which are ignorance, environmental factors, lack of adequate competent medical personnel who are capable of putting the disease under medical control, and insufficient preventive measures against the spread of the concerned ailment. Out of the previously mentioned reasons for syphilis prevalence, it has been found that the lack of competent medical personnel who are capable of providing
Medicare is the major cause of its prevalence. The annual increase in the population of syphilis's patients against the competent medical personnel is not balanced and in fact, calls for immediate aid.

The innovations in information technology (IT) and the need for improvement on the current state of Medicare due to the unbalanced ratio of patients to medical personnel have brought up a research interest like artificial intelligence in medicine (AIM). This area is concerned with the application of IT concepts in providing a human like Medicare to patients in various forms. These forms include the development of expert systems that could be used in providing a human expertlike diagnosis or therapy to patients or even used as support systems for growing medical personnel. Telemedicine is another area that looks into the use of telecommunication technologies in providing medical care.

However, this paper considers the development of a fuzzy system that is capable of providing approximate diagnostic services for patients who suffer from Syphilis using uncertain symptoms as inputs. This type of diagnosis is a human like diagnosis found in the field of medicine. The target for the hardware platform for executing the concerned system has been diligently chosen due to the expected coverage scope of the system since it is believed that patients of the concerned disease may not have direct access to personal computers (PCs), and other non mobile computing devices. Therefore, the fuzzy system executes on readily available mobile cell phones of patients that are infected with the concerned ailment. Also, the fuzzy system has been developed as a standalone system that does not provide distributed service. This has made the accessibility of the system available at absolutely no cost since there is no need for any internet or network connection before it is accessed.

\section{LITERATURE REVIEW}

This section provides a systematic theoretical framework for the study and it is categorically considered below: 


\section{A. Overview of Syphilis}

Syphilis is a systemic disease from the outset and is caused by the spirochaete, Treponema pallidum ( $\mathrm{T}$. pallidum) [1]. The infection can be classified as congenital or acquired (through sex or blood transfusion) [1]. Syphilis is a disease that has four stages: primary, secondary, latent and tertiary. The primary stage has been considered mild stage in this study based on its degree of severity. This stage has a symptom of sore called chancre that appears around anus, genital parts or around any other area of contact. It is always painless and may be accompanied by swollen glands but later disappears by itself.

The second stage that has been tagged moderate stage begins approximately seven weeks [3] after the sore firstly appeared. Common symptoms associated with this stage are rashes appearing on the body (palms, legs, trunk, arms, legs and so on) and mucous membrane lesion. Other accompanying symptoms include muscle ache, throat sore, fever, headache, loss of appetite, fatigue, swollen glands and so on. These symptoms last for few weeks and disappear if not treated and later enter into the latent stage. The tagged severe stage (latent) is always void of symptoms and this finally leads to the tertiary stage (very severe stage). The tertiary stage leads to death and permanent damage of the body even after it might have been treated. Difficulties in coordinating muscle movements, paralysis, gradual blindness, numbness and dementia are some of the symptoms associated with the tertiary stage.

\section{B. Overview of Medical Diagnostic Systems}

The development of medical diagnostic systems right from the onset has been considering various approaches: production rules based, Bayesian network based, statistical model based, fuzzy logic based and artificial neural network based medical diagnostic systems.

The production rules (if then rules) based medical diagnostic systems consider diagnosis using certainties. Here, all rules are formed by combining antecedents using Boolean logic operators (AND, OR and NOT). The antecedents here are symptoms or medical tests that are carried out in the laboratory. Example of such rules is:

IF (patient's body temperature is $>37$ degree Celsius AND patient complains of ache in the head) THEN (patient suffers headache)

MYCIN was one of the diagnostic systems that used this type of approach in making medical diagnostic. The diagnostic operation as mandated by the approach used demanded that all antecedents are precise and there was no room for uncertainties in its operation. This diagnosis based on certainties has made it service to be non human like. Other systems that use this system exist but discussion of these is not a focus in this paper.

Bayesian network based medical diagnostic systems operate using uncertainties and diagnosis making is always based on probability. This approach represents the probabilistic relationships existing between diseases and symptoms. Due to the mutual relationship existing between diseases and their symptoms showed by a patient, the model can mathematically compute the probability of the diseases that might be responsible for the symptoms. ORAD is an example of a medical diagnostic system that uses this probabilistic model [4]. Bayesian network based medical diagnostic systems are always prone to overestimation of uncommon but important features and underestimation of important common features [4] [5] due to its probabilistic reasoning nature.

Statistical based medical diagnostic model operates based on the frequencies of occurrence of some diseases in an area. A region might be facing some outbreaks of diseases say " $A$ " and "D". When a patient shows some symptoms that are associated with disease " $A$ " and " $B$ " in such an area, the patient might be diagnosed to be suffering from " $\mathrm{A}$ " since disease " $\mathrm{A}$ " is found occurring mostly in the region. This diagnostic service here is not always precise and mostly error prone.

The Fuzzy logic based medical diagnostic systems are effective with the handling of diagnostic service is approximately equal to the human like way of diagnosing. It handles diagnosis using uncertainties. Although it uses rules like we have in production rules based approach but, the rules here are fuzzy rules that are based on approximation and not on exactness. Reasoning here is fuzzy based and not a probabilistic one as contained in the Bayesian network systems. It is always most effective if this approach of diagnostic system development is combined with the artificial neural network approach of medical diagnostic system. The later approach is based on the natural working method of human neural network.

\section{Related Work}

The research interest of artificial intelligence in medicine (AIM) is not a few years old. It is therefore believed to have been some various forms of research works in the field that all attempted applying concepts in artificial intelligence (AI) into solving some problems in medicine. This paper will only review some literatures that are directly related to the topic under discourse.

A computer assisted diagnostic system for red eye was developed in [6] using visual basic programming language, Microsoft excel and some other tools. It was found to operate on the approach of production rules that is always based on certainties. This system was found to have assisted in delivering Medicare to patients who suffered red eye ailment in the remote parts where medical practitioners did not exist or were inadequate. This system due to its approach of operation could not provide a fuzzy based diagnostic that is always inherent in medicine.

Reference [7] considers the representation of knowledge in expert system using two formats: rule based and case based. The concerned hybrid of knowledge representation was found effective in that the rule based could provide deductive reasoning while the case based would provide analogical reasoning. However, in [8], there was the consideration for medical diagnostic architecture using rule based technique.

Moreover, a work in [10] there was a proposal for a framework that could construct a fuzzy expert system for mobile users. This fuzzy expert system could diagnose 
viral infections that use host cells to reproduce and disturb the immune system. However the concerned system proposed here would be a distributed system that will have its presentation layer residing on the handheld devices of the users while the functional part of the system will be residing on a web server. This makes the system not to be easily accessible to those who are not connected to the internet due to one reason or the other.

In [11], there was a consideration for the development of a mathematical model tagged generic medical fuzzy expert system for diagnosing cardiac diseases. This system was capable of providing a human like diagnostic service for cardiac diseases. It was found to operate on uncertainties and vagueness found in knowledge and information and finally provides an approximate reasoning that result into diagnosis. There was also an attempt for the justification of the system's performance.

A neuro-fuzzy system for investigating psychosomatic disorders was proposed in [12]. Fuzzy values were fed as inputs into the system to feed forward multilayer neural network. This network was trained using back propagation training algorithm. This trained network was finally tested with new patient's symptoms and signs so as to evaluate the diagnostic capability of the system. This system was compared with Bayesian network based system and statistical model based diagnostic system and found most effective because it provided a human like diagnostic service.

A fuzzy expert system approach using multiple experts for dynamic follow-up of endemic diseases was considered in [13]. In this paper, a knowledge based system for online diagnosis and monitoring prognosis of leprosy was presented. The system was developed around a fuzzy expert-system building tool fext to deal with the used imprecise knowledge.

All the considered literatures in this section of the paper have not been found considering the development of fuzzy based system that would provide diagnostic service for syphilis. Many of the considered literatures have truly attempted the development of diagnostic systems that could help in providing Medicare in various forms but few have used theories in fuzzy logic to provide a human like diagnostic service. Out of the few that provided fuzzy like solutions, little fraction of it proposed making the solutions available on mobile devices for mobility. However, this paper will help to provide a fuzzy based diagnostic system that will be mobile and capable of diagnosing syphilis using imprecise knowledge.

\section{RESEARCH METHODOLOGY}

\section{A. Materials}

The materials that are used for the development of the system are software and hardware based. The software based materials are: J2ME (java 2 micro edition), Netbeans 7.0.1 (an integrated development environment), RMS (record management system- a relational like management system integrated into J2ME for MIDLet), 32-bit Windows 7 professional (operating system) and
ClamshellCldcPhone1 Emulator. The hardware materials include: a PC with Intel(R) dual CPU T3400 @ 2.16GHz, $2 \mathrm{~GB}$ of random access memory, and Nokia X2 (for testing).

\section{B. Methods}

The mobile based fuzzy system for diagnosing syphilis (MBFSDS) considered in this paper has four components as shown in fig.1.The user interface component uses the common graphic user interface method of computerhuman interaction method. This type of method allows the use of graphics and other multimedia elements for providing friendly and easier interaction with the MBFSDS.

The fuzzification component (component that does conversion of scalar quantity to fuzzy quantity) uses the interval-valued and S-shaped membership functions. The knowledge base has fuzzy rules contained in it. The defuzzification (conversion of fuzzy quantity back to scalar quantity) of the output of inference engine has been achieved using the weighted average method (discrete form of center of gravity method). Drawing of conclusion within the inference engine has been achieved using root sum square as modeled in (1).

\section{User Interface}

The user interface is the component of the system through which users interact with the developed system. It uses the graphic user interface (GUI) human-computer interaction method for easier interactivity. The users here are the patients that suffer from syphilis, medical students and even young medical practitioners who may want to acquire more experiential knowledge that have been extracted from experts in the area of syphilis diagnosis. It displays medically approved symptoms that are known to be associated with the presence of syphilis to a user and it provides the users the opportunity of interacting with the symptoms through a select event.

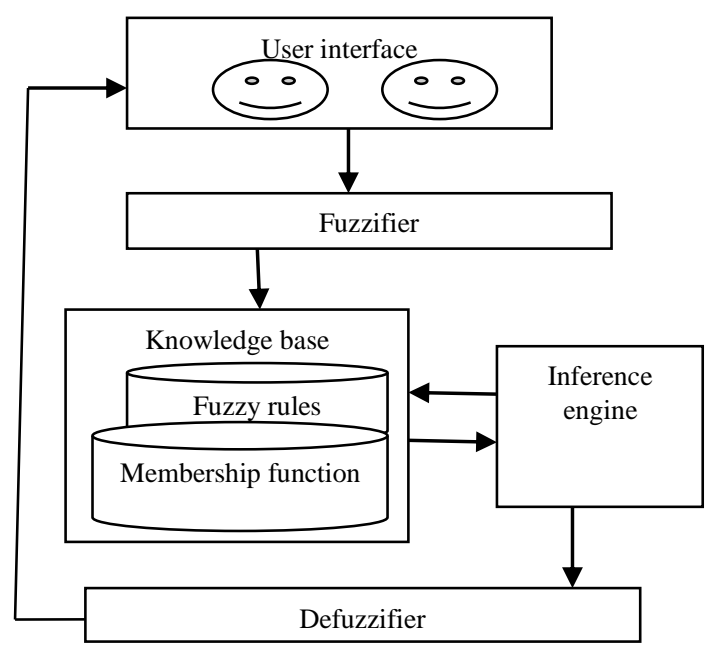

Fig. 1. Architecture of MBFSDS

Selection of a symptom by a patient is fuzzy in nature and not precise as we have in other previously developed diagnostic systems. A user chooses the degree of severity to which the symptom is been suffered. This severity 
ranges from mild to very severe (mild, moderate, severe, very severe) and not like the yes or no reply inherent in some diagnostic systems.

\section{D.Fuzzification Component}

Fuzzification is the process of transforming crisp or scalar quantities into fuzzy quantities. Various fuzzifiers (membership function) exist that are used during the transformation of crisp quantity to fuzzy quantity. These fuzzifiers are classified as ordinary and interval-valued fuzzifiers. Among the ordinary fuzzifiers are S-shaped (S-curve), reverse S-curve (Z-curve), trapezoidal and triangular membership function. However, having effectiveness coupled with reduced computational complexity in mind has prompted the use of S-shaped and interval-valued membership functions in this paper.

According to the knowledge extracted from medical personnel and some medical literatures, syphilis has been described decomposable into four stages: primary, secondary, latent and tertiary. These stages of syphilis have been tagged in this paper according severity of the disease as mild (primary), moderate (secondary), severe (latent) and very severe (tertiary). From this universe of discourse, an interval-valued fuzzy set $\mathrm{S}$ was generated and its membership function is shown in fig. 2 .

That is,

$\mathrm{S}=\left\{\left(\right.\right.$ mild, $0.1<=\mu_{\mathrm{S}}($ mild $\left.)<0.3\right),\left(\right.$ moderate, $0.3<=\mu_{\mathrm{S}}$ (moderate) $<0.6$ ), (severe, $0.6<=\mu_{\mathrm{S}}$ (severe) $<0.8$ ), (very severe, $0.8<=\mu_{\mathrm{S}}$ (very severe) $\left.\left.<=1.0\right)\right\}$

The interval values represented above are based on the medical expertise of medical practitioners who are good at diagnosing syphilis.

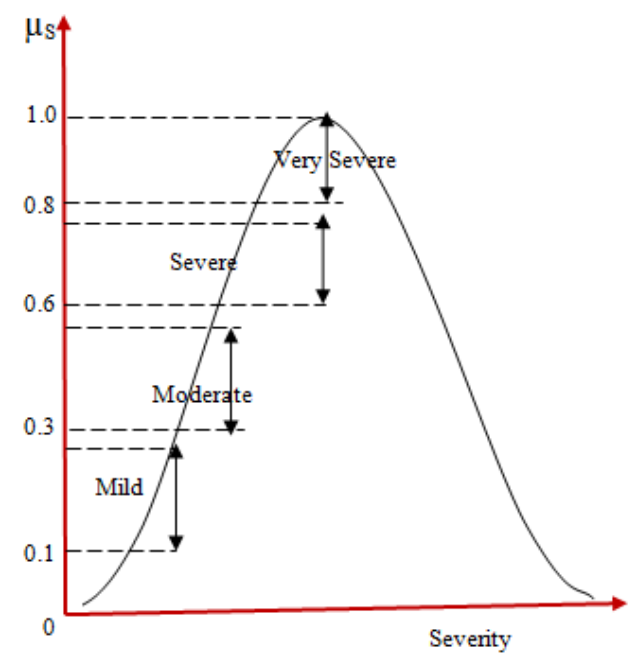

Fig. 2. Interval-valued memberships function for fuzzy set (S).

Table 1. Range of fuzzy interval values for fuzzy set (S)

\begin{tabular}{|c|c|}
\hline Fuzzy variables & Fuzzy interval values \\
\hline Mild & $0.1 \leq \mathrm{x}<0.3$ \\
\hline Moderate & $0.3 \leq \mathrm{x}<0.6$ \\
\hline Severe & $0.6 \leq \mathrm{x}<0.8$ \\
\hline Very severe & $0.8 \leq \mathrm{x} \leq 1.0$ \\
\hline
\end{tabular}

This interval-valued set can further been generalized by making each interval an ordinary fuzzy set. This type of fuzzy set in this paper is referred to as type 2 fuzzy set.

Given a type 2 fuzzy set $M$ that contains patients of syphilis at its primary stage (mild stage) and the degree of severity of the ailment based on the number of weeks to which the disease has been manifesting, its fuzzy set is represented as:

$\mathrm{M}=\{(1,0.2),(2,0.4),(3,0.6),(4,0.8),(5,1.0),(6,1.0)$, $(7,1.0)\}$

The membership function for the ordinary fuzzy set $M$ is shown in fig. 3 using the S-curve type.

Also, for the interval moderate that contains patients of syphilis at its secondary stage and the degree of severity based on the number of weeks to which the disease has been manifesting, ordinary fuzzy set for this is also shown as:

$$
\begin{array}{r}
\mathrm{N}=\{(8,0.2),(9,0.4),(10,0.6),(11,0.8),(12,1.0),(13, \\
1.0)\}
\end{array}
$$

The membership function for fuzzy set $\mathrm{N}$ is shown in fig.4.

For the latent stage of syphilis that is tagged by the severe interval in fig.2, an ordinary fuzzy set $\mathrm{O}$ can be extracted. That is,

$\mathrm{O}=\{(14,0.2),(15,0.4),(16,0.6),(17,0.8),(18,1.0)$, $(19,1.0),(20,1.0),(21,1.0)\}$

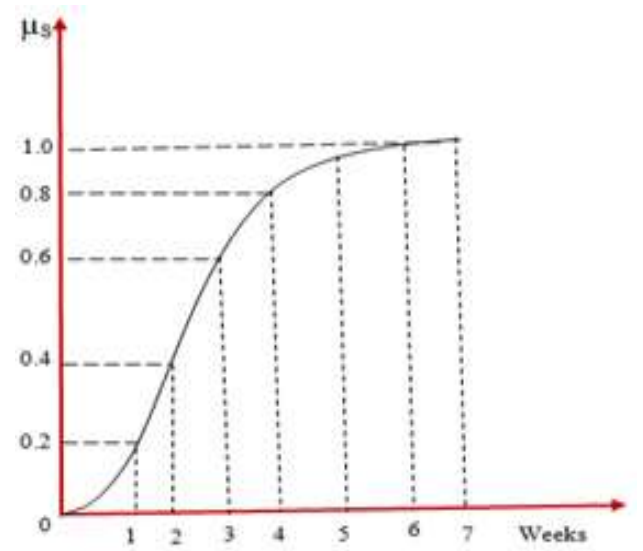

Fig. 3. Ordinary membership function for fuzzy set (M)

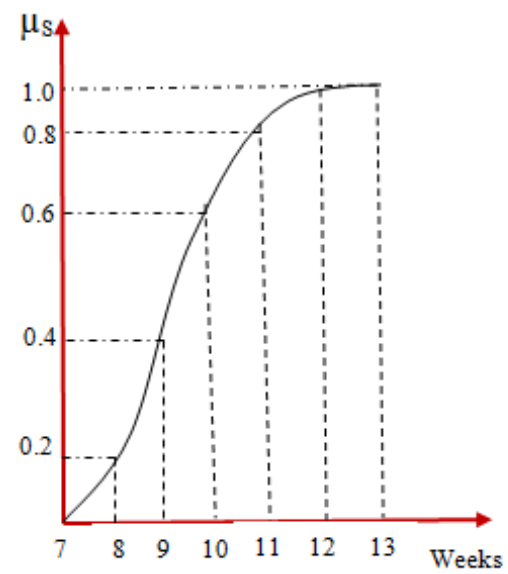

Fig. 4. Ordinary membership function for fuzzy set $(\mathrm{N})$ 
The membership function for fuzzy set $(\mathrm{O})$ is shown in fig.5.

The tertiary stage of syphilis that is tagged the very severe stage has its ordinary fuzzy set represented as:

$\mathrm{P}=\{(24,0.2),(25,0.4),(26,0.6),(27,0.8),(28,1.0)$, $(29,1.0),(30,1.0),(31,1.0)\}$

The membership function for the set $(\mathrm{P})$ is shown in fig. 6

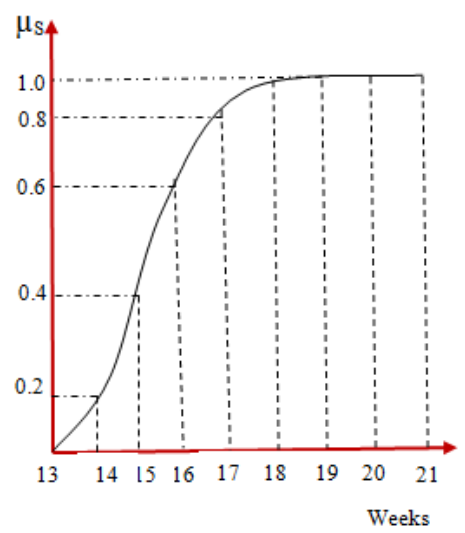

Fig.5. Ordinary membership function for fuzzy set (O)

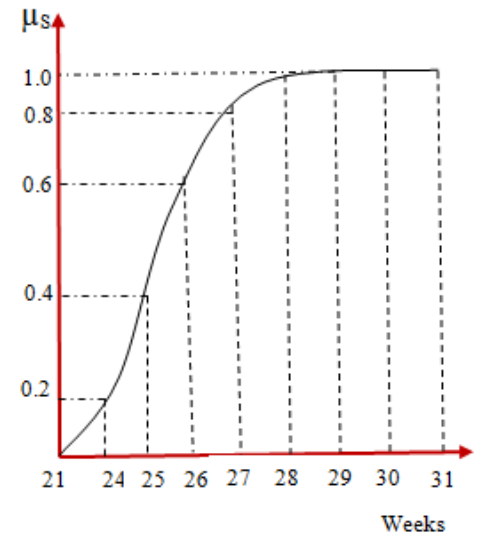

Fig. 6. Ordinary membership function for fuzzy set (P)

Table 2. Symptoms associated with each stage of syphilis and corresponding tags used in the study

\begin{tabular}{|c|c|c|}
\hline $\begin{array}{c}\text { Syphilis } \\
\text { Stage }\end{array}$ & Symptoms associated & $\begin{array}{c}\text { Tag based } \\
\text { on severity }\end{array}$ \\
\hline Primary & Sore like chancre & Mild \\
\hline Secondary & $\begin{array}{c}\text { Rashes, mucous membrane } \\
\text { lesion, throat sore, fever, } \\
\text { headache, loss of appetite, } \\
\text { fatigue, swollen glands }\end{array}$ & Moderate \\
\hline Tertiary & No symptoms & Severe \\
\hline & $\begin{array}{c}\text { Numbness, dementia, gradual } \\
\text { blindness, paralysis, difficulty in } \\
\text { muscle movement's coordination }\end{array}$ & Very Severe \\
\hline
\end{tabular}

\section{E. Knowledge Base}

The knowledge base of every expert system is the component that stores the extracted knowledge (human expertise) in a computer understandable form. The knowledge here is represented as fuzzy rules that are in the form of if..... Then. The if parts are called the antecedents while the then parts are called the consequents. This is represented as:

If (antecedents) then (consequents).

The knowledge represented in the knowledge base within this paper was extracted from experts and medical literatures. This knowledge is represented in the form of if-then rules that contains the consequents and antecedents. The antecedents are the symptoms that are associated with syphilis while the consequents are diagnostic conclusions based on the corresponding symptoms. Some of these fuzzy rules are presented in table 3 .

From the table 3 , the following is the full meaning of the abbreviated terms used: $\mathrm{Mi}$ - mild; Mo-moderate; $\mathrm{Se}$-severe; VS - very severe; $\mathrm{Ch}$ - chancre (painless sore); Ra-rashes; Les - mucocutaneous lesions; Mamuscular ache; Ts- sore throat; $\mathrm{Fe}$-fever; $\mathrm{Ha}-$ headache; $\mathrm{La}-$ loss of appetite; $\mathrm{Fa}$-fatigue; $\mathrm{Sg}$ swollen glands; $\mathrm{Pa}$-paralysis; $\mathrm{Mc}$-problem with muscle's movement coordination; Bl—gradual blindness; $\mathrm{Nu}$-numbness and $\mathrm{De}$ - dementia.

Discussion on the fuzzy rules as presented in table 3 is as follows:

Rule No 1: A patient with 0.2 degree of chancre which is the mild (primary) stage of syphilis as a symptom would have a conclusion of 0.2 percent of primary stage of syphilis.

Rule No 13: A patient with 1.0 degree mild of syphilis and who has mostly 0.2 degree moderate of syphilis would be diagnosed of having 0.2 degree of moderate syphilis.

\section{$F$. Inference Engine}

The inference engine is the component of an expert system that carries out reasoning based on available premises. It can be said to be a component that draws conclusion from available premises. There are different models that consider reasoning with uncertainties: Bayesian model- model based on probabilistic reasoning and statistical model. However, this paper will consider the use of fuzzy reasoning that is based on reasoning with uncertainties.

There are various methods for fuzzy reasoning: Max Min- that considers the magnitudes of all applicable rules and select the highest one while the horizontal coordinate of the centroid of the area under the membership function is gotten as the output; Max product; Averaging and Root sum square (RSS).

The mathematical complexity of the root sum square has been viewed by some as a setback for the use of it but, it is still the best of all the available methods since it provides the best weighted influence to all firing rules. Therefore, this study has employed the use of this method and it is mathematically modeled as:

$$
\mathrm{RSS}=\sqrt{\sum_{k=1}^{n} \mathrm{R}_{\mathrm{k}}^{2}}
$$

Where: 
" $R$ " stands for the firing strength or satisfactory strength.

" $n$ " stands for arbitrary number of fuzzy rules concerned.

\section{G.Defuzzification Component}

This is the component that handles the transformation of fuzzy quantities obtained from inference engine into scalar quantities. There are various methods available for the conversion of fuzzy quantities to scalar quantities. These are: height method (max membership), centriod (center of gravity or area) method, weighted average method, mean max membership method and center of sums among others. In this paper, center of gravity method has been used for deffuzification of fuzzy values to crisp values. This method is mathematically modeled as:

$$
\mathrm{K}^{*}=\frac{\sum \mu_{S}(K) \cdot K}{\sum \mu_{S}(K)}
$$

Where, " $K$ " is the centroid of each symmetric membership function. $\sum$, stands for summation and $\mu_{\mathrm{S}}(\mathrm{K})$ is the membership value for $\mathrm{K}$

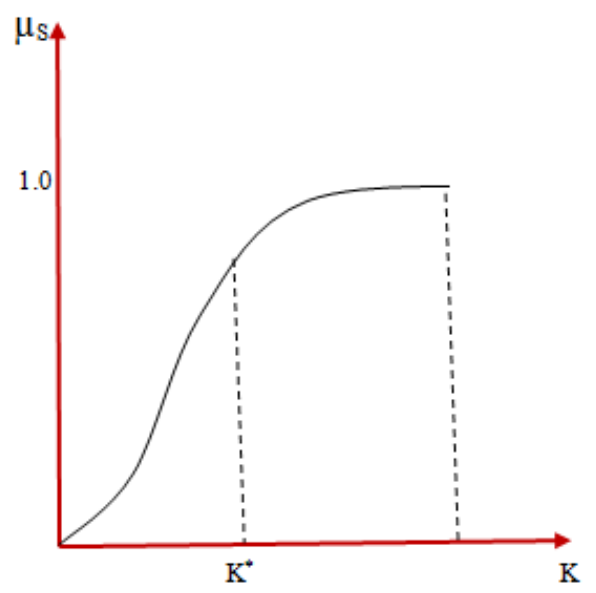

Fig. 7. Center of gravity method for defuzzification

\section{EXPERIMENTAL PILOT}

Given a patient that possesses the following fuzzified symptoms: mild (1.0) of chancre; $\bmod (0.2)$ of rashes; mod (0.6) of mucocutaneous lesion; mod (0.2) of throat sore; mod (0.4) of fever; mod (0.6) of headache; mod (0.4) of loss of appetite; mod (0.2) of swollen glands.

The fuzzified inputs when compared with the antecedents that are contained in the fuzzy rules shown in table 3.3 caused fifteen rules $(5,6,7,8,9,10,11,12,13$, $14,15,16,17,18$, and 19) to be fired. The fuzzy reasoning making use of root sum square is as follows:

From (1),

$$
\begin{aligned}
\mathrm{RSS}=\sqrt{\sum_{k=1}^{n} \mathrm{R}_{\mathrm{k}}^{2}} \\
\text { Mild }=\sqrt{R_{11}^{2}+R_{12}^{2}}=\left((0.4)^{2}+(1.0)^{2}\right)^{0.5} \\
=(0.16+1)^{0.5}=(1.16)^{0.5} \approx 1.077
\end{aligned}
$$

Moderate $=$

$$
\begin{aligned}
& \sqrt{R_{6}^{2}+R_{7}^{2}+R_{8}^{2}+R_{10}^{2}+R_{13}^{2}+R_{14}^{2}+R_{15}^{2} R_{17}^{2}} \\
& =\sqrt{0.4^{2}+0.2^{2}+0.2^{2}+0.8^{2}+0.2^{2}+0.2^{2}+0.2^{2}+0.2^{2}} \\
& \quad=(0.16+0.04+0.04+0.64+0.04+0.04+0.04+0.04)^{0.5} \\
& =(1.04)^{0.5}=1.0198
\end{aligned}
$$

\begin{tabular}{|c|c|c|c|c|c|c|c|c|c|c|c|c|c|c|c|c|}
\hline \begin{tabular}{|l|l|} 
Rule \\
No
\end{tabular} & Ch & Ra & Les & $\mathrm{Ma}$ & Ts & $\mathrm{Fe}$ & $\mathrm{Ha}$ & aا & $\mathrm{Fa}$ & $\mathrm{Sg}$ & $\begin{array}{lll}\mathrm{Pa} \\
\mathrm{a}\end{array}$ & Mc & BI & Nu & $\mathrm{De}$ & Conclusion \\
\hline $1:$ & $\mathrm{Mi}(0.2)$ & - & - & - & - & - & - & - & - & - & - & - & - & - & - & $\operatorname{Mi}(0.2)$ \\
\hline 2 & $\mathrm{Mi}(0.4)$ & $=$ & $=$ & $=$ & $=$ & $=$ & $=$ & $=$ & $=$ & $=$ & $=$ & $=$ & $=$ & $=$ & 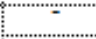 & $M i(0.4)$ \\
\hline 3 & $M i(0.8)$ & $=$ & $=$ & $=$ & $=$ & $=$ & $=$ & $=$ & $=$ & $=$ & $=$ & $=$ & $=$ & - & $=$ & $\operatorname{Mi}(0.8)$ \\
\hline 4 & $\operatorname{Mi}(0.6)$ & $=$ & $=$ & $=$ & $=$ & $=$ & $=$ & - & $=$ & $=$ & $=$ & $=$ & $=$ & $=$ & $=$ & $\operatorname{Mi}(0.6)$ \\
\hline 5 & $M i(1.0)$ & $\operatorname{Mo}(0.8)$ & $M o(0.8)$ & $M o(1.0)$ & $M o(0.8)$ & $M o(0.8)$ & $M o(0.8)$ & $M o(0.8)$ & $\operatorname{Mo}(0.8)$ & $\operatorname{Mo}(0.8)$ & $V s(0.2)$ & $V s(0.2)$ & $V s(0.2)$ & $V s(0.2)$ & $V s(0.2)$ & $S e(0.8)$ \\
\hline 6 & $M i(1.0)$ & $M o(0.6)$ & $M o(0.6)$ & $\mathrm{Mo}(0.6)$ & $\mathrm{Mo}(0.8)$ & $\operatorname{Mo}(0.4)$ & $\mathrm{Mo}(0.4)$ & $M o(0.4)$ & $M o(0.4)$ & $\mathrm{Mo}(0.2)$ & - & $=$ & $=$ & $=$ & $=$ & $M o(0.4)$ \\
\hline 7 & $\mathrm{Mi}(1.0)$ & $M o(0.4)$ & $\operatorname{Mo}(0.2)$ & $\mathrm{Mo}(1.0)$ & $M o(0.8)$ & $M o(0.4)$ & $\mathrm{Mo}(0.4)$ & $\mathrm{Mo}(0.4)$ & $\mathrm{Mo}(0.4)$ & $\operatorname{Mo}(0.2)$ & 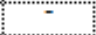 & 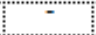 & $"$ & $=$ & $=$ & $\operatorname{Mod}(0.2)$ \\
\hline 8 & $M i(1.0)$ & $M o(0.4)$ & $M o(0.6)$ & $M o(1.0)$ & $M o(0.8)$ & $M o(0.2)$ & $M o(0.8)$ & $M o(0.6)$ & $M o(0.4)$ & $M o(0.6)$ & $\cdots$ & $=$ & - & $=$ & 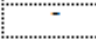 & $\operatorname{Mod}(0.2)$ \\
\hline 9 & $M i(1.0)$ & $M o(1.0)$ & $M o(1.0)$ & $M o(1.0)$ & $M o(1.0)$ & $M o(1.0)$ & $M o(1.0)$ & $M o(1.0)$ & $M o(1.0)$ & $M o(1.0)$ & $V s(0.2)$ & $V s(0.2)$ & $V s(0.4)$ & $V s(0.2)$ & $V s(0.6)$ & $V s(0.2)$ \\
\hline 10 & $M i(1.0)$ & $M o(1.0)$ & $M o(0.8)$ & $M o(0.8)$ & $M o(1.0)$ & $M o(0.8)$ & $M o(0.8)$ & $M o(0.8)$ & $M o(0.8)$ & $M o(1.0)$ & 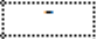 & 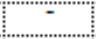 & 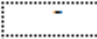 & 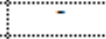 & $=$ & $M o(0.8)$ \\
\hline 11 & $\operatorname{Mi}(0.8)$ & $\operatorname{Mod}(0.4)$ & $=$ & $=$ & - & $-\quad-$ & $-\cdots$ & $=-$ & $=-$ & $=$ & $=$ & $=$ & $=$ & - & $=$ & $\operatorname{Mi}(0.4)$ \\
\hline 12 & $M i(1.0)$ & - & $=$ & $=$ & $=$ & $=$ & $=$ & $=$ & $=$ & $=$ & $=$ & 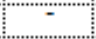 & $=$ & $=$ & $=$ & $M i(1.0)$ \\
\hline 13 & $M i(1.0)$ & $\mathrm{Mo}(0.2)$ & $\mathrm{Mo}(0.2)$ & $\mathrm{Mo}(0.2)$ & $\mathrm{Mo}(0.4)$ & $\mathrm{Mo}(0.2)$ & $\mathrm{Mo}(0.2)$ & $\mathrm{Mo}(0.2)$ & $\mathrm{Mo}(0.2)$ & $\mathrm{Mo}(0.2)$ & $=$ & $=$ & $=$ & $=$ & $=$ & $\mathrm{Mo}(0.2)$ \\
\hline 14 & $M i(1.0)$ & $\operatorname{Mo}(0.2)$ & $M o(0.2)$ & $\mathrm{Mo}(0.2)$ & $\mathrm{Mo}(0.2)$ & $\mathrm{Mo}(0.4)$ & $\mathrm{Mo}(0.4)$ & $\mathrm{Mo}(0.4)$ & $M o(0.2)$ & $\mathrm{Mo}(0.2)$ & $=$ & $=$ & $=$ & $=$ & $=$ & $M o(0.2)$ \\
\hline 15 & $M i(1.0)$ & $M o(0.2)$ & $M o(0.2)$ & $\mathrm{Mo}(0.2)$ & $\mathrm{Mo}(0.8)$ & $M o(0.2)$ & $M o(0.4)$ & $M o(0.6)$ & $M o(0.4)$ & $M o(0.4)$ & $=$ & $=$ & $=$ & 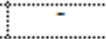 & 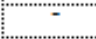 & $M o(0.2)$ \\
\hline 16 & $M i(1.0)$ & $\operatorname{Mo}(1.0)$ & $\operatorname{Mo}(1.0)$ & $M o(1.0)$ & $M o(1.0)$ & $M o(1.0)$ & $M o(1.0)$ & $\mathrm{Mo}(1.0)$ & $\operatorname{Mo}(1.0)$ & $\mathrm{Mo}(0.8)$ & $V s(0.2)$ & $V s(0.2)$ & $V s(0.4)$ & $V s(0.2)$ & $V s(0.2)$ & $V s(0.2)$ \\
\hline 17 & $M i(1.0)$ & $M o(0.2)$ & $M o(0.6)$ & $M o(0.6)$ & $M o(1.0)$ & $M o(0.4)$ & $M o(0.8)$ & $M o(0.6)$ & $M o(0.2)$ & $M o(0.4)$ & & 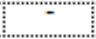 & $=$ & $=$ & & $M o(0.2)$ \\
\hline 18 & $\mathrm{Mi}(1.0)$ & $\operatorname{Mo}(1.0)$ & $\mathrm{Mo}(1.0)$ & $\mathrm{Mo}(1.0)$ & $M o(1.0)$ & $M o(1.0)$ & $M o(1.0)$ & $M o(1.0)$ & $M o(1.0)$ & $M o(1.0)$ & $\mathrm{Vs}(0.4)$ & $V s(0.2)$ & $V s(0.6)$ & $V s(0.6)$ & $\mathrm{Vs}(0.6)$ & $\mathrm{Vs}(0.2)$ \\
\hline 19 & $\mathrm{Mi}(1.0)$ & $\operatorname{Mo}(1.0)$ & $\mathrm{Mo}(0.8)$ & $\operatorname{Mo}(1.0)$ & $\mathrm{Mo}(0.8)$ & $\mathrm{Mo}(0.8)$ & $\mathrm{Mo}(0.6)$ & $\mathrm{Mo}(0.8)$ & $\operatorname{Mo}(1.0)$ & $\mathrm{Mo}(0.4)$ & & $V s(0.4)$ & $=$ & & & $\operatorname{Se}(0.4)$ \\
\hline
\end{tabular}

Severe $=\sqrt{R_{5}^{2}+R_{19}^{2}}$

$$
=\sqrt{0.8^{2}+0.4^{2}}=(0.64+0.16)^{0.5}=0.89443
$$

Very severe $=\sqrt{R_{9}^{2}+R_{16}^{2}+R_{18}^{2}}$

$$
=\sqrt{0.2^{2}+0.2^{2}+0.2^{2}}=(0.04+0.04+0.04)^{0.5}=0.34641
$$

Table 3. Some of Fuzzy Rules in the Knowledge Base 
This fuzzy outputs from the inference engine could be defuzzified using the concerned defuzzification method that is, weighted average as modeled in equation (2) to get a crisp output.

\section{CONCLUSION AND RECOMMENDATION}

This paper has considered providing a mobile based software system that could help in providing a diagnostic service to patients of syphilis especially in areas where there are inadequate or no Medicare to the patients due to reasons topped by an unequal ratio of syphilis patients to competent practitioners. The system has represented extracted medical knowledge in its knowledge base and this knowledge has been applied into providing a human like diagnostic service as found in the field of medicine. This developed system can be easily accessed by patients at little or no cost due to its operational network independence (e.g. internet). This system can also be used by medical students who want to learn more about diagnosing syphilis.

Although this system could provide an effective diagnostic service for patients of syphilis but, there should be a future attempt that will consider a system which integrates all sexually transmitted diseases together. Also there should be a need for considering many medical experts for better multiple expertise.

\section{ACKNOWLEDGMENT}

The authors wish to acknowledge the effort of all who have in one way or the other contributed to the success of this study. Mr. J. O. Owoseni of Applied Geology Department, Federal university of Technology, Akure, Nigeria receives a special acknowledgement for been a good academic role model.

\section{REFERENCES}

[1] http://www.who.int/reproductivehealth/topics/rtis/treatmen t_syphilis.pdf, [retrieved on 3/14/2014].

[2] D. Aadland, D. Finnoff and X.D. Huang, "Syphilis Cycles", 2012 retrieved from: http://www.uwyo.edu/ aadland/research/syphiliscycles.pdf on 26/03/2014.

[3] https://www.vdh.virginia.gov/epidemiology/factsheets/pdf/ Syphilis.pdf, [retrieved on 3/14/2014].

[4] A. Ameri and H. Moshtaghi, "Design and development of an expert system in differential diagnosis of maxillofacial radio-lucent lesions", retrieved from http://www.idt.mdh.se /kurser/ct3340/ archives/ht08/papersRM08/21.pdf on $15 / 3 / 2014$

[5] L. S. Goggin, Robert H. Eikelboom, and Marcus D Atlas, "Clinical decision support systems and computer aided diagnosis in otology," Otolaryngology-Head and Neck Surgery, 136:S21-S26, 2007.

[6] M. Z. Asghar, A. R. Khan, and M. J. Asghar, "computer assisted diagnoses for red eye (CADRE)," International Journal of Computer Science \& Engineering, vol. 1(3), pp 163-170, 2009.

[7] H. H. Owaied, and M. M. Qasem, "Developing rule-casebased shell expert system," Proceedings of International
Multi Conference of Engineers and Scientists, 2010, retrieved from: http://www.iaeng.org/publication /IMECS 2010 _pp81-91.pdf on 15/3/2014.

[8] P. P. Tomar, and P. K. Saxena, "Architecture for medical diagnosis using rule-based technique," First International Conference on Interdisciplinary Research \& development, Thailand, vol. 25, pp. 1-25, 2011.

[9] M. H. F. Zarandi, M. Zolnoori, M. Moin, and H. Heidarnrjad, "A fuzzy rule based expert system for diagnosing asthma," Industrial Engineering, vol. 17 (2), pp. 129-142, 2010.

[10] M. Patel, and P. Virparia, "Designing mobile based fuzzy expert system framework for viral infection diagnosis", International Journal of Current Research and Review, vol. 4(12), pp. 139-146, 2012.

[11] S. S. Smita, S. Sikchi and M. S. Ali, "Generic medical fuzzy expert system for diagnosis of cardiac diseases," International Journal of Computer Applications, vol. 66, no. 13, pp. 35-44, 2013.

[12] P. Aruna, N. Puviarasan and B. Palaniappan, "An investigation of neuro-fuzzy system in psychrosomatic disorders," Expert Systems with Applications, vol. 28, pp 673-679, 2005.

[13] A. Banerjee, A.K. Majumdar and A. Basu, "A fuzzy expert system approach using multiple experts for follow-up of endemic diseases," sadhana, India, vol. 19(1), pp. 51-73, 1992.

\section{Authors' Profiles}

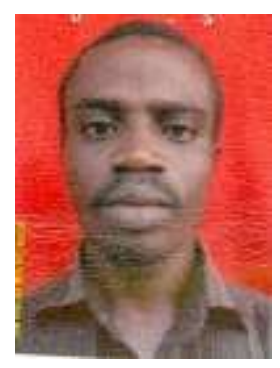

Alaba T. Owoseni was born in Ipetu Ijesa of Osun State, Nigeria in 1984. He had his bachelor of technology (BTech) in computer engineering from Ladoke Akintola University of Technology, Ogbomoso, Nigeria in 2009 and as at the time of conducting this research, he was awaiting his oral defense for master of technology (MTech) in computer science at Federal University of Technology,

Akure, Nigeria.

$\mathrm{He}$ is currently a lecturer at department of Computer Science Interlink Polytechnic, Ijebu Jesa, Osun State, Nigeria. His research interests include multi-valued logic, artificial intelligence (AI), information retrieval, programming logic, software engineering, and database management system.

Mr. Owoseni is currently a member of International Association of Engineers; International Association for Computer Science and Information Technology; and few societies of International Association of Engineers.

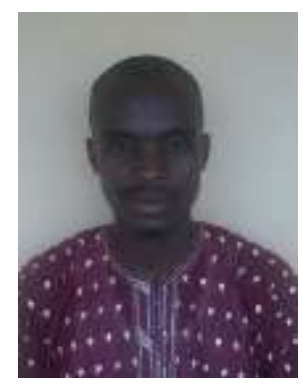

Isaac O. Ogundahunsi was born in Ilesa of Osun State, Nigeria in 1979. He had his ND and HND in Computer Science from Osun State College of Technology, Esa Oke and Osun State Polytechnic, Iree. He also had Postgraduate Diploma in Computer Science (PGDCS) from Federal University of Technology, Akure. He had his Bachelor of Science (Bsc) in Computer Science from Joseph Ayo Babalola University, Ikeji Arakeji. He is currently preparing for his masters degree in computer science.

$\mathrm{He}$ is currently a lecturer in the department of Computer Science, Interlink Polytechnic, Ijebu Jesa. His research interests 
include computer networks, programming logic, software engineering, and database management system.

Mr. Ogundahunsi is currently a member of International Association of Engineers.

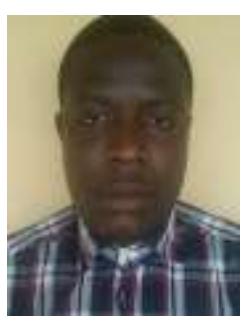

Seun Ayeni was born in Ilesa of Osun State, Nigeria in 1985 . He had his bachelor of technology (BTech) in computer engineering from Ladoke Akintola University of Technology, Ogbomoso, Nigeria in 2009 and as at the time of conducting this research, he was undergoing his Master of Science (MSc) degree in computer science at Obafemi Awolowo University, Ile Ife, Nigeria.

$\mathrm{He}$ is currently an assistant lecturer at department of Computer Engineering Interlink Polytechnic, Ijebu Jesa, Osun State, Nigeria. His research interests include artificial intelligence (AI), Information system analysis and design, software engineering, and database management system.

Mr. Ayeni seun is currently a member of International Association of Engineers.

How to cite this paper: Alaba T. Owoseni, Isaac O. Ogundahunsi, Seun Ayeni,"A Mobile-Based Fuzzy System for Diagnosing Syphilis (Sexually Transmitted Disease)", International Journal of Information Technology and Computer Science(IJITCS), vol.7, no.1, pp.33-40, 2015. DOI: 10.5815/ijitcs.2015.01.04 